\title{
Using Evidence in Practice
}

\section{Services in a Changing Academic Library: Patron Feedback and Library Response}

Bruce Stoffel

Reference Coordinator and Associate Professor

Milner Library, Illinois State University

Normal, Illinois, United States of America

Email: brstoff@ilstu.edu

Received: 12 June 2009

Accepted: 07 October 2009

(C) 2009 Stoffel. This is an Open Access article distributed under the terms of the Creative Commons Attribution License (http://creativecommons.org/licenses/by/2.0), which permits unrestricted use, distribution, and reproduction in any medium, provided the original work is properly cited.

\section{Setting}

Illinois State University is a comprehensive research institution enrolling 20,856 (Fall 2009) including 18,344 undergraduates and 2,512 graduate students. Graduate degree offerings include both Master's and doctoral studies. The University began in 1857 as a teacher training school and became a comprehensive university in 1964 . The University employs 3,200 including approximately 1,000 faculty members. Milner Library is a six-story facility that opened in 1976 and serves as the single library facility on campus accessible to students, faculty, and staff. Library holdings total approximately 1.5 million volumes. Floor 1 (basement) is configured with staff offices and closed storage. Floors 2-6 are public areas with a mix of shelving, study areas, and group study rooms.

\section{Problem}

From the opening of Milner Library in 1976 through summer 2007, the library was zoned by floor according to broad subject areas. Each floor functioned much like a separate library, with its own monographs, serials, reference holdings, reference services, offices, and staff. In 2006-2007, library administration developed a plan to reorganize collections and service points. The plan was a response to deteriorating physical conditions on Floor 1 (the education, psychology, and teaching materials library), patron demand for additional study space, and decreasing patronage of reference service points. In advance of the fall 2007 term, reference materials and services were consolidated on the main floor (Floor 2). Lesser-used library materials were relocated from upper floors to a new closed storage area in the basement (Floor 1). Emptied shelving areas on upper floors were then removed to create additional seating and study spaces.

Library staff members were concerned about the impact of these changes on library patrons. Specifically, staff members were concerned whether patrons were satisfied with reference service consolidation and changes to the library physical environment. 


\section{Evidence}

A reference working group was organized in early spring 2008 to survey the campus community about these issues. Research approval was obtained from the campus institutional review board. Authorization was received from campus administration to contact students, faculty, and staff with an email message that included a link to an online survey (on SurveyMonkey). The survey was available during the last two weeks of April 2008. Two e-mail notices were sent to prospective respondents, an initial invitation and a reminder. No other methods were used to stimulate response. Participation in the survey was voluntary.

Our goal was a $100 \%$ survey of the students, faculty, and staff. However, our campus policy allows members of the campus community to block research solicitations sent by e-mail. Consequently, we sent e-mail invitations to approximately $70 \%$ of the campus community, or about 17,000 persons. To save time we did not use stratified sampling techniques nor did we use techniques to limit respondents to one response. As a result, the profile of both e-mail recipients and respondents did not precisely match the profile of the campus community at large. Although a few respondents may have completed the survey more than once, our close scrutiny of responses to open-ended survey questions did not identify duplicate entries.

We asked both closed- and open-ended questions. Regarding reference, we asked which reference services respondents were aware of and used, the reasons why respondents asked for help from library staff, and how satisfied they were with assistance they received. To probe opinions about physical changes, we asked respondents to rate cleanliness, lighting, study space, computers, furnishings, and security. Because opportunities to conduct campus-wide surveys are limited, we took this opportunity to also ask questions about research behaviour and library services other than reference.
Of the persons solicited, 2,152 started the survey and 1,815 completed it, for a return rate of approximately $10 \%$. Respondents were almost entirely library users. Ninety-six percent indicated that they come to the library at least once a semester, and 97\% indicated that they use the library Web site at least once a semester. We were pleased with these numbers, because our primary interest was receiving feedback from library users rather than non-users.

Respondents expressed high levels of familiarity with desk reference services (95\%) but significantly lower levels with telephone (41\%), e-mail (49\%), and IM (40\%).

Differences between desk and other reference services in terms of usage were more pronounced. Eighty-nine \% of respondents indicated having asked questions at the reference desk, but only $18 \%$ indicated having asked by telephone, $23 \%$ by e-mail, and $12 \%$ by IM. We were particularly concerned with the lower figures for remote reference services but of their potential use in serving patrons working on floors no longer served by reference desks.

Ninety-five percent of respondents indicated that they usually or always find help in the building when they need it, and 90\% expressed satisfaction with availability of staff members at the time of their need. We did not directly ask about closure of service points but anticipated receiving comments about this in response to two open-ended questions: one asking patrons to describe a negative library experience, and another asking patrons what they would do to make the library more helpful to them. Of the 948 negative experiences described by survey respondents, 40 (or approximately $4 \%$ ) related to availability of reference services. Of the nearly 900 suggested changes, 36 related to restoring service points on all floors (also approximately $4 \%$ ). We concluded from these numbers that while improvement was possible in providing reference services remotely to persons on our upper floors, dissatisfaction with reference consolidation was not great enough to warrant reversing the consolidation. 
A majority of respondents indicated being satisfied with all aspects of the library physical environment we asked them to rate. However, amount of group study space received the lowest satisfaction rating $(62 \%)$. Levels of dissatisfaction were highest for furnishings $(20 \%)$ and the amount of quiet study space $(19 \%)$. Twenty-four percent of survey respondents choosing to identify a negative library experience cited excessive building noise. Twelve percent of respondents who suggested a way to make the library more helpful to them mentioned better separation or enforcement of quiet study space. An additional $12 \%$ of the suggested changes related to increasing study space or study rooms, but it was unclear from the responses whether respondents were concerned with spaces for quiet or group study. Concern about building noise was likely heightened because we conducted the survey right before our finals week. However, we concluded from these responses a need for actions to reduce noise levels in the building, particularly in designated quiet study areas and particularly during peak study weeks.

\section{Implementation}

A primary goal resulting from the survey was to increase familiarity with and use of remote reference services available to patrons seeking assistance while on unstaffed floor, particularly IM. At the time we were advertising our IM screen name on our website. In late spring 2008 we organized a working group to review our IM reference service. The result of this review was introduction of an IM widget accessible from all library Web pages beginning in August 2008. The reason for this change was to allow patrons using our Web site to communicate with reference desk staff without having to log into their IM accounts or use cell phone minutes. About this same time we also modified the presence of our reference services on the library Web site from a small "Ask a Librarian" link to a set of "Contact us" buttons on the upper left side of all library Web pages. Separate buttons were added for IM, phone, e-mail, and in person. In fall 2009 we added a texting option to our reference service. We began distributing business cards with telephone and texting instructions to persons leaving the reference desk for upper floors, to aid them in remotely contacting the desk for follow-up service.

We also took action in response to concerns expressed by survey respondents about noise. Throughout the fall 2008 semester we promoted availability of designated quiet study areas by adding signage, advertising the spaces in library promotional materials, and urging desk staff to inform patrons of the areas if asked about places to study in the building. While these changes seemed well received by patrons, we continued to receive noise complaints during final exams week. For spring 2009 final exams we took a more aggressive approach with the goal of further reducing noise complaints. We temporarily zoned the library into quiet and group study areas by floor. We designated Floors 2 and 3 as group study floors, largely because they are open to one another in their corners, allowing noise bleed between floors. We designated Floors 4 and 5 quiet study areas for the same reason. To alert patrons to this temporary scheme we placed multiple signs and table tents throughout the building and posted announcements on the library Web site, campus Web portal, campus television network, and electronic message boards in the building. On the library homepage we featured a one-minute video of our student government president urging cooperation with the policy. Library staff members periodically roamed quiet floors to ask violators for their cooperation.

\section{Outcome}

During the first ten weeks of the fall 2008 semester, our IM reference transactions totalled 454 compared with 93 during the first ten weeks of fall 2007 (an increase of 388\%). We attributed this increase at least in part to adoption of the IM widget and enhanced visibility of the service on library Web pages. While we were unable to track the location of persons asking questions through the service, 
desk staff reported numerous instances of persons contacting the service from locations within the library. In addition, between the first ten weeks of fall 2007 and fall 2008, our telephone reference transactions increased $35 \%$. We attributed at least part of this increase to increased visibility of telephone reference on library Web pages. Data for fall 2009, including figures on usage of our new text reference service, are not yet available.

With regard to our actions to reduce library noise, we have received numerous positive comments and messages from patrons and from campus administrators. No negative comments have been received. However, we feel that a formal evaluation is warranted.

\section{Reflection}

The patron survey provided us valuable feedback regarding changes to our services and environment. The relatively large number of persons surveyed and responding helped validate our subsequent actions, likely more so than if we had instead conducted small focus groups.

It was encouraging and validating to receive positive responses. Feedback regarding our remote reference services provided the impetus for change that will hopefully further enhance patron satisfaction levels. The level of concern about building noise surprised many library staff members. We would not likely have known of the extent of the problem otherwise. Implementing the zoned study area trial was likely easier and more effective having patron feedback than if we had not conducted the survey. We used survey data as a primary justification for our actions. We prominently mentioned survey responses when promoting the trial, which we hope furthered patron cooperation. We stressed survey results when asking cooperation from our study body president.

Because our patrons and services continue to change, at a seemingly faster pace, we now plan to conduct patron surveys on a more routine basis. But because of the effort necessary to plan and implement a survey of this size and especially the time involved with analyzing responses, conducting such a survey annually would be too taxing for us. We plan instead to conduct a comprehensive patron survey every two years beginning in spring 2010. We also intend to use more advanced survey and analysis techniques, such as stratified sampling, to improve reliability and validity of survey results. We intend to utilize the services of a research consultant to help improve to survey design, implementation, and analysis.

\section{Acknowledgement}

The author acknowledges the work of Illinois State University colleagues Christine Kubiak Diane Mather, Julie Murphy, Sharon Naylor, and Jenna Self on design and implementation of the survey described in this article. 